\title{
A Utilização de Kits de Robótica como Ferramenta para o Ensino de Programação à Meninas do Ensino Médio
}

\author{
Giorgia de Oliveira Mattos ${ }^{1}$, Danielle Rousy Dias da Silva ${ }^{1}$, Josilene Aires Moreira ${ }^{1}$ \\ ${ }^{1}$ Centro de Informática - Universidade Federal da Paraíba (UFPB) \\ Av. dos Escoteiros - s/n - Distrito Industrial de Mangabeira \\ 58055-000 - João Pessoa-PB \\ \{giorgia,danielle,josilene\}@ci.ufpb.br
}

\begin{abstract}
One of the difficulties of women entering in computer science area is that they do not feel capable or able to deal with technology. This report describes the strategy of use of robotics as a training tool in programming and Computer Science disclosure for girls. The activities took place in a Public high school in João Pessoa, PB. The school provided its robotics kits and the activities were divided into two phases. In Phase 1, the robots were mounted and phase 2 the girls made programs to test the functionality specific to the kit model like turn on your headlights and sound the buzzer.
\end{abstract}

Resumo. Uma das dificuldades do ingresso de mulheres na área de Ciência da Computação é que, em geral, elas não se sentem aptas nem capazes de lidar com a tecnologia. O presente relato descreve a estratégia de utilização da Robótica como instrumento da capacitação em Programação e da divulgação da Ciência da Computação para meninas, realizada em uma Escola Pública de Ensino Médio na cidade de João Pessoa-PB. A escola disponibilizou os seus kits de robótica para as atividades que foram divididas em duas fases. A fase 1 consistiu na montagem dos robôs e a fase 2 no desenvolvimento de programas que testaram as funcionalidades especificas para o modelo de kit utilizado, como por exemplo como acender os faróis e soar a buzina.

\section{Introdução}

A programação de computadores é uma das bases na formação de profissionais da área de computação. Programar consiste em escrever, utilizando uma linguagem de programação, instruções que, quando executadas, resolvem um determinado problema de forma automatizada [Cristóvão 2008]. Essa não é uma tarefa fácil, pois é preciso entender o problema, encontrar uma solução e organizá-la em uma sequência lógica e revisar a solução proposta para o problema.

Habilidades como a criatividade, o raciocínio lógico e a capacidade para a resolução de problemas são fundamentais para o sucesso na programação e estas devem ser estimuladas durante toda a formação escolar do aluno. O ensino da computação desde a educação básica, passando pelo ensino fundamental e médio, por exemplo, é 
uma abordagem que pode contribuir para o desenvolvimento de tais habilidades. Outra abordagem bastante utilizada atualmente é a robótica educacional.

A robótica educacional ou robótica pedagógica tem despertado a atenção de professores e alunos porque que ela aumenta o interesse e a criatividade dos alunos, pois eles vivenciam, na prática, através da construção de maquetes e robôs controlados por computador, conceitos estudados em sala de aula. É uma atividade lúdica e desafiadora que envolve um processo de motivação, colaboração, construção e reconstrução. A valorização do trabalho em grupo, a cooperação, o planejamento, a pesquisa e a tomada de decisões estão entre os principais pontos trabalhados pela robótica educacional [Azevedo, Aglaé e Pitta 2010].

Assim, esse trabalho relata as atividades desenvolvidas em uma Escola Pública de Ensino Médio na cidade de João Pessoa-PB utilizando kits de robótica educacional no primeiro contato de alunas com a programação de computadores. As atividades realizadas envolveram o estudo do processo de montagem do robô com a identificação e seleção das peças, a montagem propriamente dita com o encaixe delas e a programação do robô do tipo explorador. O público participante foram alunas que estavam do primeiro ao terceiro ano do ensino médio. Nesse sentido, a seção 2 apresenta os trabalhos relacionados, na seção 3 são apresentados os motivos da escolha do público alvo feminino e a seção 4 descreve as atividades desenvolvidas, metodologias utilizadas e formas de avaliação. E por fim, a seção 5 traz as considerações finais.

\section{Trabalhos Relacionados}

A robótica educacional vem sendo utilizada em diversos trabalhos há algumas décadas. Em 1976 Seymour Papert um dos pioneiros, criou o software livre Logo. O Logo permite que crianças aprendam programação de uma forma lúdica e motivadora [Solomon e Papert1976].

Attrot e Ayrosa mostraram a utilização da robótica educacional para o ensino da disciplina de Compiladores [Attrot e Ayrosa 2002]. Uma nova linguagem de programação, chamada WELIX, e seu respectivo compilador, para uso com o Kit MindStorms da LEGO foram desenvolvidos.

Kits de robótica educacional da Lego [Lego 2009] juntamente com a linguagem Logo foram utilizados no experimento realizado com alunos do ensino médio envolvendo assuntos relacionados com as disciplinas de geografia, matemática e programação de computadores [Benitti, Vahldick, Urban, Krueger e Halma 2009]. De acordo com os autores, os resultados observados são promissores principalmente considerando a motivação dos alunos para retornarem ao laboratório de robótica para realizar outras oficinas.

Outra abordagem para à introdução de conceitos de algoritmos e programação de computadores utiliza a música como instrumento de ensino para algoritmos e a robótica para o ensino de programação [Silva, Silva e Melo 2011]. Com noções de conceitos musicais e a utilização de um pandeiro, associado à ideia de executar um conjunto de instruções para produzir uma saída desejada, foram abordados conceitos de algoritmos. A correspondência entre os algoritmos do cotidiano com algoritmos computacionais foi feita utilizando a robótica. A programação de robôs trabalhou 
conceitos de pseudocódigo e noções de programação com a finalidade de fazer o robô andar em todas as direções e mostrar mensagens no visor. Os alunos mostraram-se bastante receptivos com as atividades desenvolvidas.

Dinâmicas realizadas com alunos do ensino superior em computação são mostradas por Soares [Soares e Borges 2011]. Tais dinâmicas seguiram a metodologia ProblemBased Learning (PBL) [Bellström e Kilbrink 2010] onde o aluno é o responsável pela criação do aprendizado e o professor por selecionar o problema a ser resolvido e ser o facilitador da atividade. Primeiramente os alunos utilizaram kits de robótica educacional para a familiarização com a robótica e conceitos que utilizaram mais tarde. Posteriormente os alunos construíram seus próprios robôs. Um dos objetivos foi mostrar para os alunos o seu potencial na construção do próprio conhecimento e a aptidão para aprenderem e se adaptarem a qualquer tipo de linguagem.

De maneira geral, os diversos autores tem relatado que a utilização da robótica educativa pode ser uma forma de complementação do processo de ensino de computação nos mais diversos níveis da educação. A robótica pode apoiar os professores facilitando o aprendizado dos alunos e também o entendimento dos conceitos ensinados em sala de aula.

\section{Público Alvo: Porque Apenas Meninas?}

Pesquisadores de todo o mundo têm questionado o porquê da desigualdade de gênero nas áreas de Ciência e Tecnologia, particularmente na Computação [Reis, Mattos e Moreira 2014]. Estudos recentes mostram que, mesmo em países desenvolvidos como os Estados Unidos, a presença feminina é bastante reduzida [Beaubouef e Zang 2011]. O Instituto Europeu de Informática relata dados sobre o ingresso de estudantes por gênero na Suíça, Holanda, Reino Unido, dentre outros países mostrando que a presença feminina chega, no máximo, a $10 \%$, índice muito baixo quando comparado com a presença masculina [Pereira e Meyer 2013].

O Brasil acompanha o cenário mundial. Segundo o INEP - Instituto Nacional de Estudos e Pesquisas Educacionais Anísio Teixeira, foi constatado que nos anos de 2012 e 2013, o número de mulheres que ingressaram, matricularam e concluíram a educação superior no Brasil se mostrou maior do que o número de homens [Inep 2014]. Porém, é notável que a preferência dos cursos escolhidos pelo público feminino fica restrita às áreas de humanas e saúde. Já entre o público masculino, os dados mostram que as áreas de maior inserção estão ligadas às exatas, como as engenharias e cursos relacionados à tecnologia e à computação.

Dentre as causas mais citadas para o desinteresse pela computação por parte das mulheres está a falta de modelos femininos na área, o fato das mulheres se sentirem excluídas em ambientes, estudantis ou profissionais, dominados por homens, a falta de incentivo para que sigam uma carreira na área e o fato de não se sentirem a vontade com a cultura da computação [Burge e Suarez 2005] [Beaubouef e Zang 2011] [Eney, Lazowska, Martin e Reges 2013] [Dubow 2013] [Klawe 2013].

A fim de reverter essa situação e preparar melhor as meninas para o que vão encontrar em cursos da área de computação, inúmeras iniciativas no Brasil e no mundo [Info 2014] tem surgido com o objetivo de informar e incentivar as meninas a 
ingressarem na área de computação. No Brasil, o Women in Information Technology WIT é uma iniciativa da Sociedade Brasileira de Computação (www.sbc.org.br) para discutir os assuntos relacionados a questões de gênero e a Tecnologia de Informação no Brasil - histórias de sucesso, políticas de incentivo e formas de engajamento e atração de jovens, especialmente mulheres, para as carreiras associadas a Tecnologia da Informação. Universidades como UFMT (http://www.ufmt.br/mulheresnacomputacao), UNICAMP [Anunciação 2014] e outras mantém projetos nas diversas áreas da computação com o objetivo de incentivar as próprias alunas dos cursos de computação bem como parcerias com escolas do ensino médio.

O Centro de Informática da UFPB - Universidade Federal da Paraíba, em João Pessoa, através do projeto Mulheres na Ciência da Computação: Despertando vocações através da difusão do conhecimento, aprovado pela chamada pública Meninas e jovens fazendo Ciências Exatas, Engenharias e Computação ( ${ }^{\circ} 18 / 2013$ MCTI/CNPq/SPM$\mathrm{PR} /$ Petrobras), iniciou um conjunto de ações junto à Escola Pública Estadual de Ensino Médio Matheus Augusto de Oliveira. O objetivo do projeto é a divulgação dos cursos da área de computação oferecidos pela UFPB bem como as carreiras e perspectivas do mercado de trabalho na área [Silva 2014]. Dentre as ações desenvolvidas está a utilização da robótica educacional para o ensino da programação de forma lúdica, descrita aqui nesse relato.

Logo, a escolha do público alvo feminino se deu em função dos motivos explicitados acima.

\section{Atividades Realizadas}

Esta seção descreve as atividades desenvolvidas, o material utilizado, a metodologia adotada e a forma de avaliação junto às alunas do ensino médio. Participaram dessa ação três professoras do Centro de Informática da UFPB e quatro alunas de graduação, três do curso de Ciência da Computação e uma do curso de Engenharia da Computação.

As atividades envolvendo a robótica educacional foram feitas na Escola Pública Estadual de Ensino Médio Matheus Augusto de Oliveira, na cidade de João Pessoa-PB, junto às turmas do primeiro, segundo e terceiro anos. Essa escola faz parte do ProEMI Programa Ensino Médio Inovador, cuja intenção é estimular as redes estaduais de educação a pensar novas soluções que diversifiquem os currículos com atividades integradoras, a partir dos eixos trabalho, ciência, tecnologia e cultura, para melhorar a qualidade da educação oferecida nessa fase de ensino e torná-la mais atraente. Assim, as atividades foram realizadas no período da tarde, durante aproximadamente três meses, num total de cinco encontros.

João Pessoa, através do Governo do Estado da Paraíba, no ano de 2008 atendeu cerca de trinta mil alunos de esfera pública nos projetos que envolvem a robótica educacional [Daoun 2008]. A Escola recebeu um conjunto de kits de Robótica Fischertechnik (http://www.fischertechnik.de/) com a função de auxiliar o processo ensino-aprendizagem em disciplinas que fazem parte do currículo do ensino médio. O kit ROBO TX Explorer foi cedido para a realização das atividades.

As atividades foram desenvolvidas com 8 alunas do ensino médio envolvendo o primeiro, segundo e terceiro anos. Não houve um processo de seleção formal para a 
participação nas atividades, apenas o interesse e a motivação das alunas em participar. Essas 8 meninas dividiram-se entre si e formaram 4 duplas de acordo com a afinidade entre elas. Cada dupla trabalhou com um kit de robótica.

As alunas bolsistas da graduação, supervisionadas pelas professoras do Centro de Informática da UFPB, foram responsáveis pelo planejamento, elaboração de material de apoio, execução e avaliação das atividades.

\subsection{Fase 1: a montagem}

O primeiro passo foi fazer a integração entre as alunas bolsistas da graduação e as alunas da Escola através de uma pequena explanação sobre a robótica, suas aplicações e o nosso objetivo com a utilização dos kits disponíveis. As alunas da Escola dividiram-se em 4 duplas e passaram à organização do material a ser utilizado para a montagem efetivamente dos robôs, identificando e separando as peças a serem utilizadas. Após isso, deram início ao processo de montagem da estrutura mecânica do robô, conforme mostrado na Figura 1.
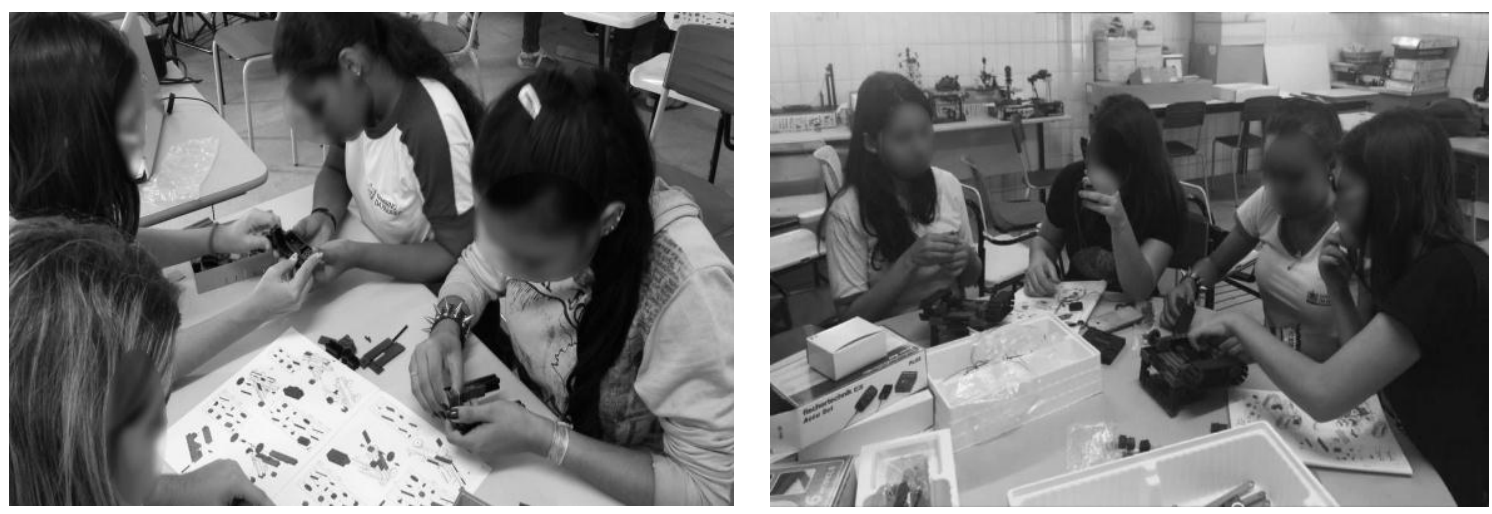

Figura 1. Processo de montagem do robô.

Terminada a montagem mecânica, passou-se à montagem da parte eletrônica com a identificação dos componentes (bateria, sensores, motores, buzina e faróis) a serem ligados e sua conexão através da fiação. A Figura 2 mostra os quatro robôs com a mecânica e a elétrica finalizadas. Esses robôs possuem faróis, buzinas, dois motores e luz traseira.

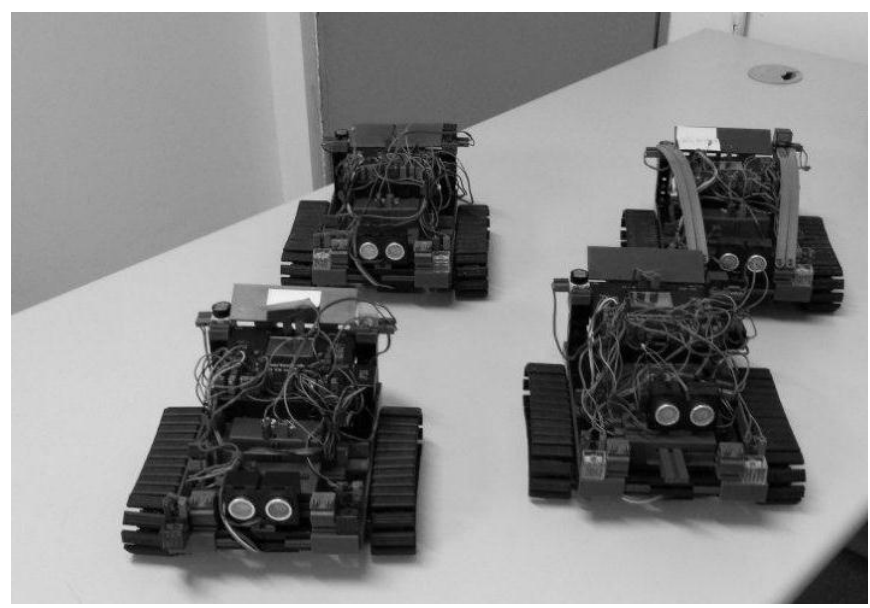

Figura 2. Robô montado com a finalização da parte elétrica. 


\subsection{Fase 2: a programação}

Os kits disponíveis contam com um ambiente de programação chamado ROBO Pro. Ele permite a construção do código em forma de fluxograma e divide a programação em níveis, do mais básico ao mais complexo envolvendo objetos, rotinas, variáveis e comandos definidos pelo programador. $\mathrm{O}$ ambiente do ROBO Pro está ilustrado na Figura 3. Ao término da codificação é necessário transferir o programa feito para o robô a fim de testá-lo. Essa transferência é feita usando a porta USB.

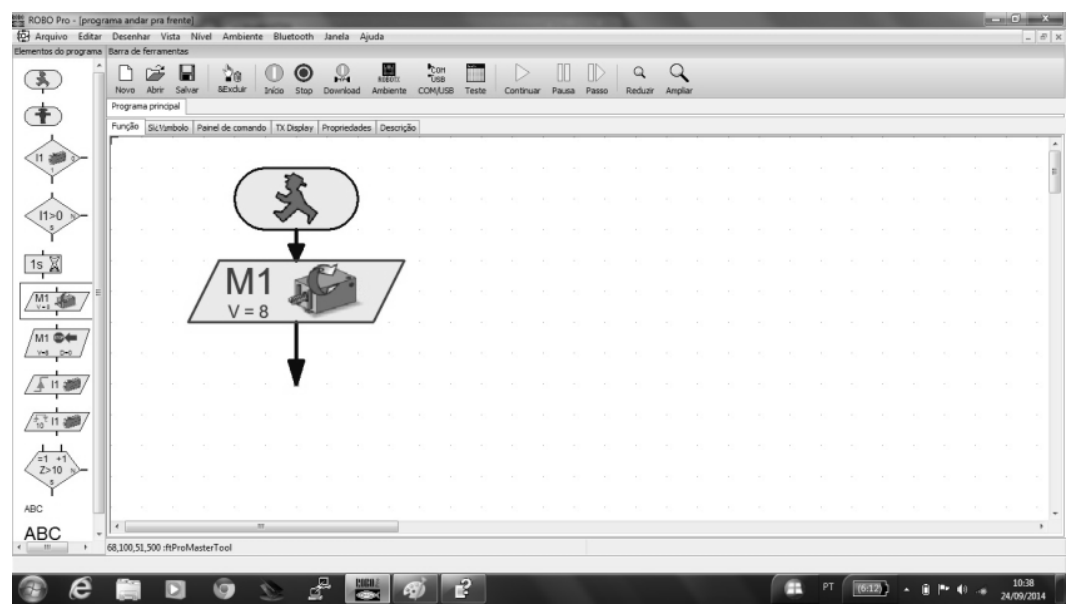

Figura 3. O ambiente de programação ROBO Pro.

As alunas começaram construindo pequenos programas como ligar o motor, andar por três segundos, parar e desligar o motor. Sempre ao término de cada tarefa uma tarefa desafiadora era proposta e assim, de uma maneira lúdica e divertida elas tiveram o seu primeiro contato com a área de programação.

Os conceitos de programação trabalhados nessa fase foram as estruturas de controle de execução de um programa, sequencial, condicional e de repetição. Conceitos de níveis intermediários como subprogramas também foram trabalhados. A tarefa de andar por 3 segundos e parar gerou um subprograma que foi utilizado algumas vezes à medida que o nível de dificuldade dos problemas foi aumentando. A Figura 4 mostra as atividades de programação e teste do robô sendo executadas.
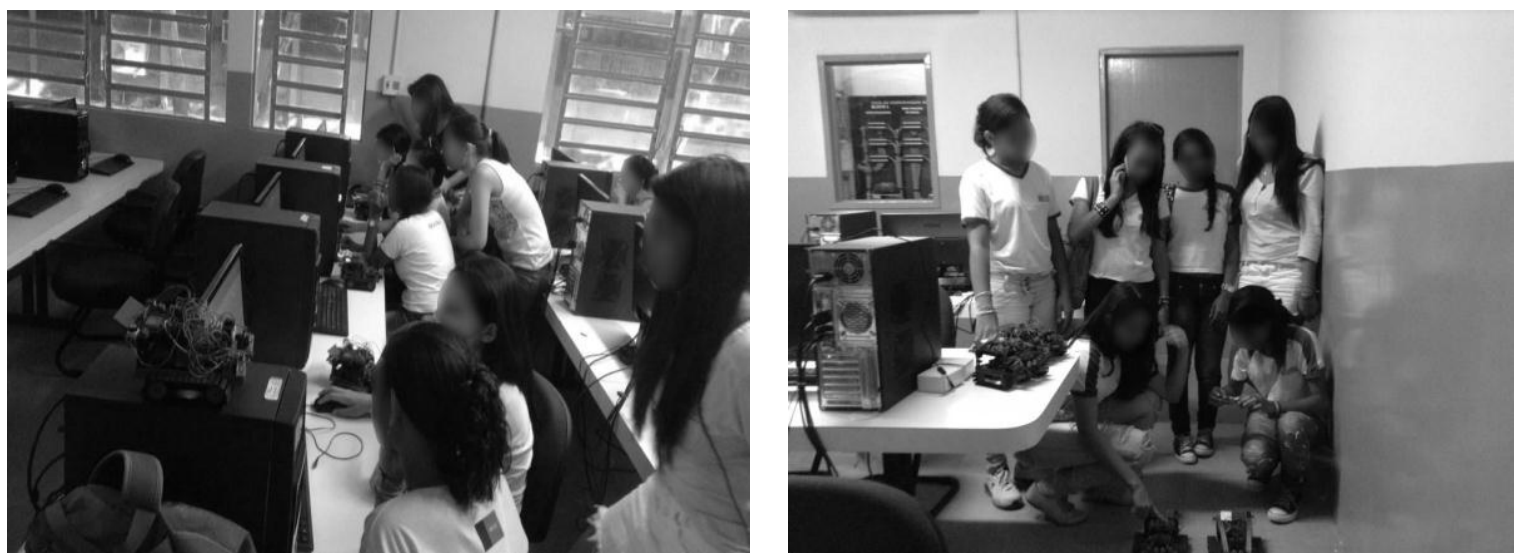

Figura 4. A programação e o teste do Robô. 


\subsection{A avaliação das atividades}

No primeiro encontro com as alunas da Escola foi aplicado um questionário com questões abertas a fim de detectar os conhecimentos prévios de robótica e programação, o grau de dificuldade da tarefa, caso a aluna já tivesse tido algum contato com o tema, e o nível de motivação/interesse no curso. Das oito alunas que responderam o questionário, apenas uma já havia montado um robô e considerou fácil a montagem. Em relação à programação apenas uma aluna já havia tido contato com comandos de programação de robôs em nível básico. $80 \%$ das meninas estavam motivadas em aprender o assunto.

Nesse mesmo questionário havia também sete questões de lógica. A média de acertos do grupo ficou em $28 \%$. Mesmo a aluna que já tinha algum conhecimento de programação não chegou a obter metade dos acertos. Os resultados mostraram que o raciocínio lógico deveria ser trabalhado ao longo das atividades. Outra possibilidade seria envolver as disciplinas de Matemática e Física, por exemplo, na construção de atividades que pudessem ajudar a melhorar esse índice.

A avaliação das atividades foi feita através das rodas de conversa ao final de cada encontro onde as alunas descreviam como tinha sido aquela atividade para elas, identificando as suas dificuldades e o seu grau de satisfação. A avaliação pela equipe executora foi através da observação da execução da atividade e a verificação se, ao seu término, esta havia sido cumprida ou não. De maneira geral as alunas da Escola se mostraram motivadas, interessadas pela atividade que estava sendo desenvolvida e com a vontade de aprender mais.

Em entrevista realizada com as alunas do ensino médio, com relação à carreira que pretendiam seguir no futuro nenhuma delas considerou, inicialmente, a carreira de Computação. As carreiras mais citadas foram as de policial militar e médica, apenas uma aluna considerou carreira na área de tecnologia citando a arquitetura. Ao término das atividades propostas, duas alunas se mostraram bastante motivadas e consideraram a possibilidade de seguir na área de Computação.

\section{Considerações Finais}

A utilização da robótica educacional tem se mostrado eficaz como ferramenta de auxílio para o professor trabalhar conceitos dos mais diversos tipos. Utilizá-la para o ensino da programação também, uma vez que conceitos importantes como algoritmos e programação são trabalhados de forma lúdica e o aluno fica longe da problemática de que programar é difícil, porque ele aprende brincando.

Esse relato descreveu as atividades de ensino da programação, utilizando a robótica educacional, com 8 meninas de uma escola de ensino médio da cidade de João Pessoa. As únicas exigências para a participação na atividade foram a motivação e o interesse em participar. O público masculino não foi considerado nessa experiência visto que a atividade desenvolvida faz parte de uma das ações de um projeto maior chamado Mulheres na Ciência da Computação, desenvolvido no Centro de Informática da UFPB, contemplado na chamada pública $\mathrm{N}^{\mathrm{o}} 18 / 2013$ MCTI/CNPq/SPM-PR/Petrobras. O objetivo dessa chamada é despertar o interesse do público feminino para as áreas de tecnologia onde a sua presença é minoria. 
A experiência da robótica educacional junto ao público feminino, como primeira ferramenta para o estudo de conceitos de programação foi extremamente satisfatória. As alunas trabalharam em duplas sempre discutindo o que estavam fazendo e planejando a execução da fase seguinte. Elas se sentiram motivadas e desafiadas com a atividade visto que até então nunca tinham trabalhado com os kits. $\mathrm{O}$ fato de constatarem que foram capazes de montar e programar o robô gerou uma grande satisfação pessoal. Foi através dessas atividades que elas tiveram contato com o mundo da computação e não apenas como usuárias de jogos, redes sociais ou outros aplicativos.

\section{Referências}

Anunciação, S. (2014) Lugar de menina é na computação. Jornal da Unicamp. n. 595.

Attrot, W. e Ayrosa, P. P. S. (2002) Aplicações da Robótica no Ensino de Ciência da Computação. WEI - X Workshop sobre Educação em Computação, Florianópolis, Santa Catarina.

Azevedo, S., Aglaé, A. e Pitta, R. (2010) Minicurso: Introdução a Robótica Educacional. $62^{\mathrm{a}}$ Reunião Anual da SBPC. Disponível em: http://www.sbpcnet.org.br/livro/62ra/minicursos/MC\%20Samuel\%20Azevedo.pdf.

Beaubouef, T. e Zhang, W. (2011) Where are the women computer science students?. Journal of Computing Sciences in Colleges, New York, v. 26, n. 4, p. 14-20.

Bellström, P. e Kilbrink, N. (2010). Problem-Based Learning in a Programming Context-Planning and Executing a Pilot Survey on Database Access in a Programming Language. In: G. A. Papadopoulos, W. Wojtkowski, G. Wojtkowski, S. Wrycza, \& J. Zupancic, Information Systems Development (pp. 867-875). Springer US.

Benitti, F. B. V., Vahldick, A., Urban, D. L., Krueger, M. L. e Halma, A. (2009) Experimentação com Robótica Educativa no Ensino Médio: ambiente, atividades e resultados. WIE - XV Workshop sobre Informática na Escola, Bento Gonçalves, Rio Grande do Sul.

Burge, J. D. e Suarez, T. L. (2005) Preliminary Analysis of Factors Affecting Women and African Americans in the Computing Sciences. Proceedings of the 2005 conference on Diversity in computing, New York, p. 53-56.

Cristóvão, H. M. (2008) Aprendizagem de Algoritmos num Contexto Significativo e Motivador: um relato de experiência. WEI - XVI Workshop sobre Educação em Computação, Belém do Pará, Pará.

Daoun, M. (2008) Alunos criativos, robôs idem. Revista Carta na Escola. Rio de Janeiro, n. 25.

Dubow, W. M. (2013) Diversity in Computing: Why It Matters and How Organizations Can Archive It. Computer, New York, v.46, n.3, p. 24-29.

Eney, C., Lazowska, E., Martin, H. e Reges, S. (2013) Broadening Participation: The Why and the How. Computer, New York, v.46, n.3, p.48-51. 
Inep. (2014) Relatório Censo da Educação Superior 2013. Instituto Nacional de Estudos e Pesquisas Educacionais Anísio Teixeira. http://portal.inep.gov.br/web/censo-daeducacao-superior, Outubro.

Info. (2014) Tecnologia é coisa de mulher. Revista Info EXAME. Editora Abril. Ed. 339.

Kenski, V. M. (2003) Tecnologias de Ensino Presencial e a Distância. Campinas: Papirus.

Klawe, M. (2013) Increasing Female participation in Computing: The Harvey Mudd College Story. Computer, New York, v. 46, n. 3, p. 56-58.

Lego Groups. (2009) Lego.com MINDSTORMS NXT Home. http://mindstorms.lego.com.

Pereira, C. e Meyer, B. (2012) Informatics education in Europe: institutions, degrees, students, positions, salaries - Key Data 2008-2012. http://www.informaticseurope.org/images/documents/informatics-education-europe-data-2008-2012.pdf

Reis, L., Mattos, G. O. e Moreira, J. A. (2014) Um Panorama da Presença Feminina na Ciência da Computação. $18^{\circ}$. REDOR. Recife-PE.

Silva, J. (2014) Mulheres na computação desperta vocações em JP. Jornal Correio da Paraíba, João Pessoa.

Silva, T. S. C., Silva, A. S. C. e Melo, J. C. B. (2011) Ensino de Algoritmos a Nível Médio Utilizando Música e Robótica: Uma Abordagem Lúdica. WEI - XIX Workshop sobre Educação em Computação, Natal, Rio Grande do Norte.

Soares, R. F. e Borges, M. A. F. (2011) Robótica: aprendizado em informática de forma lúdica. WEI - XIX Workshop sobre Educação em Computação, Natal, Rio Grande do Norte.

Solomon, C. J. e Papert, S. (1976). A case study of a young child doing turtle graphics in LOGO. AFIPS '76 Proceedings of the June 7-10, 1976, national computer conference and exposition (pp. 1049-1056). New York: ACM. 